\title{
Phenotypic response to soil compaction varies among genotypes and correlates with plant size in sorghum
}

\author{
José Correa (D) Johannes A. Postma (D) \\ Tobias Wojciechowski (D)
}

Received: 2 June 2021 / Accepted: 15 September 2021 / Published online: 5 January 2022

(C) The Author(s) 2022

\begin{abstract}
Aims Soil compaction is a major yield-reducing factor worldwide and imposes physico-chemical constraints to plant growth and development. Facing limitations, roots can adapt and compensate for loss of functioning through their plasticity. Being primarily a belowground challenge, tolerance to soil compaction needs to be associated with root phenotype and plasticity. It is therefore of importance to distinguish between size-related apparent and size-independent adaptive plasticity. We determined the above- and belowground plasticity of sorghum genotypes varying in overall plant size.

Methods We quantified plasticity as the degree response (adaptive and apparent plasticity) to soil compaction and conducted two experiments with sorghum and two soil density levels (1.4 and $1.8 \mathrm{Mg} \mathrm{m}^{-3}$ ). First, we quantified the shoot biomass plasticity of 28 sorghum genotypes. Second, we studied the root plasticity of six genotypes varying in shoot size and tolerance to soil compaction.
\end{abstract}

Responsible Editor: W Richard Whalley

Supplementary Information The online version contains supplementary material available at https://doi. org/10.1007/s11104-021-05160-z.

J. Correa $\cdot$ J. A. Postma $\cdot$ T. Wojciechowski $(\bowtie)$

Forschungszentrum Jülich, Wilhelm-Johnen Straße,

52425 Jülich, Germany

e-mail: t.wojciechowski@fz-juelich.de
Results Plasticity was correlated with plant biomass with larger genotypes responding earlier and more intensely. Soil compaction affected roots more than shoots and plasticity was expressed foremost in nodal root number and fine root length. Impeded plants produced 35 and $47 \%$ less root mass and length, respectively.

Conclusions Plasticity to soil compaction varies among genotypes, but less-sensitive lines are in general smaller-sized genotypes. The association between tolerance and plant biomass may pose challenges to crop production; however, vigorous genotypes with unresponsive shoots to soil compaction do exist. Maintaining shoot growth relatively stable while the root modifies its structure can be an important adaptation mechanism to soil compaction.

Keywords Plasticity - Genotype-by-environment interaction · Plant phenotyping $\cdot$ Root system architecture $\cdot$ Soil bulk density $\cdot$ Soil strength . Phenotypic variation

\section{Introduction}

When a genotype is able to express different phenotypes in different environments, it is called plastic (Bradshaw 1965; Correa et al. 2019; Palmer et al. 2012; Pigliucci et al. 2001; Sultan 1987; Via et al. 1995). In general, the phenotypic responses of plants can be classified into true or apparent plasticity. The 
distinction between these two types of plasticity may be challenging. Apparent plasticity is phenotypic variation that is associated with plant size and age (allometry). For example, changes in biomass allocation usually are a function of plant biomass during growth and development (allometric) (Correa et al. 2019). In contrast, plasticity may have an adaptive value, providing tolerance to several environmental constraints (Bradshaw 1965; Des Marais et al., 2013). True plasticity (or just plasticity) can encompass stress, damage, and adaptive responses. Thus, plants are thought to be able to face environmental constraints through their plasticity (Bradshaw 1965; Des Marais et al. 2013; Palmer et al. 2012; Via et al. 1995).

In crop production, stress is any condition that decreases yield (Wallace 1986). Tolerant genotypes are those that survive and produce with comparatively low yield reductions (Negin and Moshelion 2016). Since phenotypic plasticity can be associated with environmental tolerance (Bradshaw 1965; Des Marais et al. 2013), the plasticity for specific phenotypic traits is likely adaptive. The mechanism of tolerance, however, might not be readily observed when they involve belowground or physiological responses. Consequently, tolerant genotypes may be (mistakenly) seen as non-plastic because they hardly express evident phenotypic changes. Plasticity can be described as environment dependent phenotypes of a genotype. Different plant traits can vary in their plasticity to different environments and, depending on the trait, these phenotypic changes may or may not be adaptive. Apparent plasticity is given by ontogenetic effects (the phenotype depends on the size or the state of development of the plant), is relatively easily observed for size-related plant traits (Correa et al. 2019). When the environment affects plant growth, all the size-related plant traits may be influenced concordantly. This correlation between traits and plant size is called apparent plasticity or allometry. Examples for size-dependent apparent plasticity/allometry are found for drought (Blum and Sullivan 1997; Blum et al. 1997), heat (Blum et al. 1997), boron deficiency (MacInnes and Albert 1969), and soil compaction (Coelho Filho et al. 2013). The negative effect of soil compaction on shoot growth was more severe on plants harboring the tall Rht allele than semidwarf and dwarf lines (Coelho Filho et al. 2013) or commercial cultivars (Jin et al. 2015) of wheat. For example, Coelho Filho et al. (2013) showed that the leaf elongation of the taller line was more affected by mechanical impedance of roots than the semi-dwarf line. A GA-insensitive severe dwarf NIL did not show any reduction in leaf elongation by root impedance while having the smallest value of root dry mass among the Rht lines.

Soil compaction is a global issue affecting millions of hectares of agricultural lands (Oldeman et al. 1991). Specifically, soil compaction, often caused by heavy traffic of farm equipment, can negatively affect root growth and thereby nutrient and water uptake (Arvidsson and Håkansson 2014; Bengough and Mullins 1990; Bengough et al. 2011; Passioura 2002; Unger and Kaspar 1994). The degree of compaction of a particular soil depends on many soil properties, such as texture, structure, organic matter content, water potential, porosity, etc. (Atkinson et al. 2020; Kolb et al. 2017; Lucas et al. 2019; To and Kay 2005). Furthermore, root systems also affect soil by compacting the surrounding soil as they grow and leaving behind a dense net of biopores as they are degraded (Lucas et al. 2019). Yield losses by compaction have been estimated to be approximately 20 and $25 \%$ of total yield in barley and wheat, respectively (Arvidsson 1999; Barken et al. 1987). The lower yields result from reduced uptake of water and nutrients, and lower biomass, which in turn are consequences of soil mechanical impedance on root growth and development (Grzesiak et al. 2014; Håkansson et al. 1988; Lipiec and Stępniewski 1995; Passioura 2002; Stirzaker et al. 1996). The major phenotypic response of the root system to soil compaction is a reduced total root length with a coinciding increase in root diameter (Bingham et al. 2010; Colombi and Walter 2017; Eavis 1972; Goss 1977; Grzesiak et al. 2002; Pfeifer et al. 2014; Popova et al. 2016). Although some observed plasticity may be linked to negative (stress or damage) consequences for plant growth, we suggested that other changes might be adaptive and represent a possible mechanism of crop tolerance to soil compaction. To breed tolerant lines to soil compaction, tolerance needs to be associated with root system phenotype and be adaptive rather than apparent plasticity. Because little is known about the role of plasticity on the phenotypic responses to soil compaction, we studied whether the genotypic diversity in the degree of responses to soil compaction is more dependent on true plasticity than on plant 
biomass (apparent plasticity). Additionally, we examine whether those responses are expressed mainly above- or belowground. To answer these questions, we conducted two experiments in controlled environments. As a first step, we carried out a simple experiment to assess how phenotypically diverse a panel of 28 genotypic lines is in terms of shoot biomass and response to compaction. Then, in a larger and longer experiment, we investigated both the above- and belowground response of six genotypic lines which varied in overall size and tolerance to compaction.

\section{Materials and methods}

We carried out two greenhouse experiments: (1) an initial screen of 28 sorghum genotypes and (2) an in-depth phenotyping of 6 selected genotypes. In the first experiment, we grew the 28 genotypes in compacted and loose soil for 25 days to screen for differential shoot biomass responses to soil compaction and determine the relation between overall plant size (biomass) and the relative response of plant size to compaction. In the second experiment, we studied the above- and belowground phenotypic apparent and true plasticity to soil compaction in six different genotypes. These genotypes differed in their degree of shoot mass plasticity to soil compaction in the first experiment. The two experiments were carried out in the greenhouse facilities of the Institute of Bio- and Geosciences (IBG-2) at the Forschungszentrum Jülich GmbH, Germany (50 54' 36" N, 6²4' 49" E). A loam field soil (10\% clay, $38.6 \%$ silt, and $51.4 \%$ sand) was uniformly mixed, air dried until constant mass was reached, sieved to $2 \mathrm{~mm}$, and used as substrate. 28 genotypes of sorghum (Sorghum bicolor L. Moench) with diverse geographical, breeding status, and genetic origin were cultivated (Supplementary Table S1). Surface-sterilized seeds were pre-germinated at $21{ }^{\circ} \mathrm{C}$ in Petri dishes on moistened filter paper for $48 \mathrm{~h}$. We transplanted those healthy seedlings that had an intact radicle.

\section{Experiment 1}

For experiment 1, 28 genotypes were grown under two soil density treatments, loose and compacted soil. Eight replicates and two plants per replicate were used for each genotype. Seedlings were planted in pot trays composed of 60 small containers of $0.25 \mathrm{~L}$ each. Each container was filled with dry soil according to the following densities: 1.4 and $1.8 \mathrm{Mg} \mathrm{m}^{-3}$ for loose and compacted treatments, respectively. The soil was compacted homogeneously throughout the pot using a hand hammer and compacted until the required amount of soil would fit in the container. This resulted in a penetration resistance of 0.4 and $1.8 \mathrm{MPa}$, respectively for dry soil (measured with a hand penetrometer for top layers IB, Eijkelkamp, The Netherlands). After wetting the penetration resistance in the compacted treatment dropped to 1.6 $\mathrm{MPa}$. We transplanted in each container two seedlings of the same genotype. Containers were placed in trays. Each tray had one soil density level and 28 containers with in total 56 plants of 28 genotypes. 16 trays ( 8 reps, two treatments) were placed in the greenhouse according to a randomized split-block design (see Supplementary Fig. S1A).

Plants grew for 25 days from the 3rd to the 28th of July (from seedling transplanting to harvest). In addition to natural light during the day, supplementary illumination was supplied by mercury lamps (SON-T AGRO 400, Phillips, The Netherlands) every time that light intensity outside the greenhouse was $<400 \mu \mathrm{mol} \mathrm{m} \mathrm{m}^{-2} \mathrm{~s}^{-1}$ during $16 \mathrm{~h}$ between 06:00 and 22:00 h local time. Environmental conditions during the experiment were: day length of $16 \mathrm{~h}$, day/night air temperatures of ca. $26.2 \pm 0.03$ $/ 20.3 \pm 0.02{ }^{\circ} \mathrm{C}$, and day/night air relative humidity $47.1 \pm 0.11 / 66.9 \pm 0.01 \%$. The trays were watered once a week by capillary action from the bottom to the top by putting them on a bigger tray with water until they reached an on average $90 \%$ of field capacity (46 and $39 \mathrm{~cm}^{3}$ per container of gravimetric water content for loose and compacted soil, respectively) with distilled water. Water content at field capacity was determined by weighing trays after they were wet to near saturation and then drained for $48 \mathrm{~h}$. At harvest, the shoots were collected and dried in an oven at $65{ }^{\circ} \mathrm{C}$ until constant shoot mass was reached and recorded. Later, six genotypes differing in shoot dry mass and degree of plasticity to soil compaction were selected for the second experiment in which we studied root growth plasticity in relation to shoot responses. 


\section{Experiment 2}

In experiment 2, we investigated the above and belowground. In experiment 1 , six genotypes were selected that differed in their phenotypic plasticity to soil compaction in terms of shoot biomass. This is to ensure sufficient genotypic and phenotypic variation to be observed in the second experiment using a smaller number of genotypes, a larger pot size, and applying higher levels of soil compaction.

We grew the plants according to a two factorial completely randomized design with six genotypes, two soil conditions, and 12 replicates ( $n=144$ plants). We filled cuboid-shaped pots (volume $4000 \mathrm{~cm}^{3}$ ) at densities of 1.4 and $1.8 \mathrm{Mg} \mathrm{m}^{-3}$, for loose and compacted soil, respectively. The soil was compacted with a manual bolt press (Holzmann Dop 3000, Holzmann Maschinen $\mathrm{GmbH}$, Austria). The soil compression yielded penetration resistances of 0.4 and $3.1 \mathrm{MPa}$, for loose and compacted soil respectively (measured in dry columns with a hand penetrometer for top layers, Eijkelkamp, The Netherlands).

We transplanted one seedling per pot. Plants grew for 45 days from the 4th of September to the 18th of October. In addition to natural light during the day, supplementary illumination was supplied as previously indicated for experiment 1. Environmental conditions during this experiment were: day/night air temperatures of ca. $22.7 \pm 0.01 / 19 \pm 0.01{ }^{\circ} \mathrm{C}$, and day/ night air relative humidity $50.2 \pm 0.05 / 63.6 \pm 0.07 \%$. To track shoot development over time, the shoot projected area was measured non-destructively two times per week for each plant individually. The 'ScreenHouse' automated phenotyping platform of IBG-2 was used for this task (more details are found in Nakhforoosh et al. 2016, Supplementary Fig. S1). The soil water content was determined gravimetrically, and the plants were automatically watered throughout the experiment using the 'ScreenHouse' platform. Plants were irrigated with distilled water at $90 \%$ of field capacity, 730 and $620 \mathrm{~cm}^{3}$ of water per pot for loose and compacted soil, respectively. Water content at field capacity was determined by weighing pots after they were wet to near saturation and then drained for $48 \mathrm{~h}$. The volumetric water content at saturation was 0.46 and 0.30 for loose and compacted soil, respectively.

At harvest (45 days old plants), plant height and number of tillers and leaves were evaluated. Then, the shoot was cut off from the rest of the plant at the substrate surface. Leaf area and stem projected area were measured using a LI-3100C area meter (LICOR, Inc., Nebraska, USA). Afterward, roots were carefully separated from the substrate and the rest of the soil particles were washed away from the roots with water. Images of scanned roots were analyzed using WinRHIZO Pro image analysis system (Regent Instruments, Inc., Quebec, Canada) to estimate total distribution of root length by root diameter class. The root length was recorded in 25 root diameter classes equally distributed between 0 and $2.5 \mathrm{~mm}$. The root, stem, and leaf dry mass were obtained after drying it in an oven at $65{ }^{\circ} \mathrm{C}$ until constant mass. Specific leaf area and specific root length were calculated per plant as the ratio of leaf area to leaf biomass and root length to root dry mass, respectively (for a complete list of traits, see Supplementary Table S2).

\section{Statistical analysis}

A two-way Analysis of Variance (ANOVA) and an Analysis of Covariance (ANCOVA) for each trait were performed. In both analyses, genotype, soil compaction treatment and their interaction (genotypeby-treatment interaction or $\mathrm{G} \times \mathrm{T}$ ) were used as factors. For ANCOVA, plant dry mass was added to the ANOVA model and considered as a covariable. We defined the relative effect of a factor on the phenotype of a given trait as the proportion of the total phenotypic variance explained by this factor. This proportion was calculated based on the mean squares of each factor and error according to the ANOVA or ANCOVA model. Additionally, to analyze the allometric relationship between root and shoot biomass, an additional ANCOVA was computed considering the natural logarithm of root dry mass and shoot dry mass as the dependent variable and the covariable, respectively. Before these analyses, the assumptions of normality and homoscedasticity of variances of residuals were evaluated by the Shapiro-Wilks and the Levene tests, respectively. Variables that failed to meet these assumptions were transformed to natural logarithm, after which the tests were repeated successfully. Significant differences among genotypes were compared by the Fisher's test $(P<0.05)$ using the R package "agricolae" (Mendiburu 2012). Additionally, to test how significant was the treatment within each genotype a two-sample t-test was 
performed. To analyze the relationships among the traits, a correlation analysis was carried out based on Pearson's correlation coefficient between traits.

We used the fold change of the logarithm base 2 (FC2) as plasticity index for a simpler analysis of the correlation between plant biomass and the phenotypic plasticity to soil compaction. FC2 has been used for analysis and visualization especially in genomics and bioinformatics (Love et al. 2014). Thus, the phenotypic plasticity of a specific trait was expressed as the FC2 of the ratio of mean value in compacted $\left(\bar{x}_{1}\right)$ to that in loose soil $\left(\bar{x}_{0}\right)$ soil for each genotype and trait (plasticity $=\log _{2}\left[\bar{x}_{1} / \bar{x}_{0}\right]$ ). This value represents a plasticity index. The FC2 values are close to zero mean no or low plasticity whereas large negative or positive values mean strong plasticity. For example, if the plasticity value for a given trait equals -1 , it indicates that the phenotype of that specific trait under compacted conditions was half that of loose conditions. On the other hand, an FC value equal to +1 means that the phenotype of a trait under

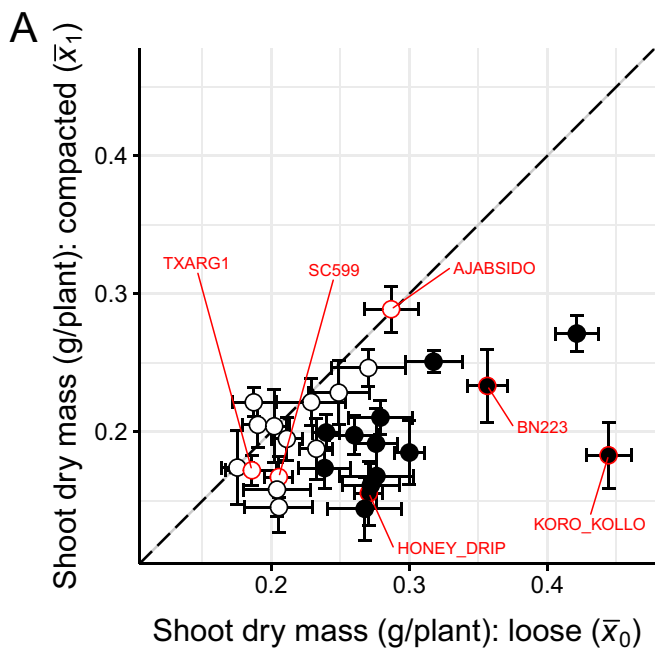

Fig. 1 Relative response of shoot dry mass to soil compaction in 3- to 4-week-old plants of 28 sorghum genotypes. A Correlation between shoot biomass under loose and compacted soil. 28 symbols show the mean and standard error of shoot dry mass for 28 sorghum genotypes plant under loose and compacted soil conditions: $\bar{x}_{0}$ and $\bar{x}_{1}$, respectively. If a genotype shows differences in terms of shoot biomass between loose and compacted conditions (t-test, $P$-value $<0.05$ ), the genotype was labeled as plastic and plotted with solid circles. Otherwise, the genotypes were labeled as non-plastic and plotted with open circles. The grey line shows the 1:1 ratio and genotypes the closest to the grey line are non-plastic (open). compaction is twice as large as that found under loose soil. Finally, hierarchical clustering of traits was performed using the R package "ClustOfVar" (Chavent et al. 2017). We analyzed all data using the $\mathrm{R}$ statistical programming language (R Core Team 2018). All the graphs were drawn using the "ggplot2" package of R (Wickham 2009).

\section{Results}

\section{Experiment 1}

Soil compaction reduced the shoot dry mass of most but not all genotypes (Fig. 1A). The compaction treatment explained $89 \%$ of the phenotypic response in shoot biomass, whereas genotype and the $\mathrm{G} \times \mathrm{T}$ explained 6 and $4 \%$ respectively (Table 1 ).

Genotypes with a significant treatment effect on shoot biomass (t-test, $P<0.05)$ were labeled 'plastic' (black dots) whereas the others were labeled as
$\mathrm{B}$

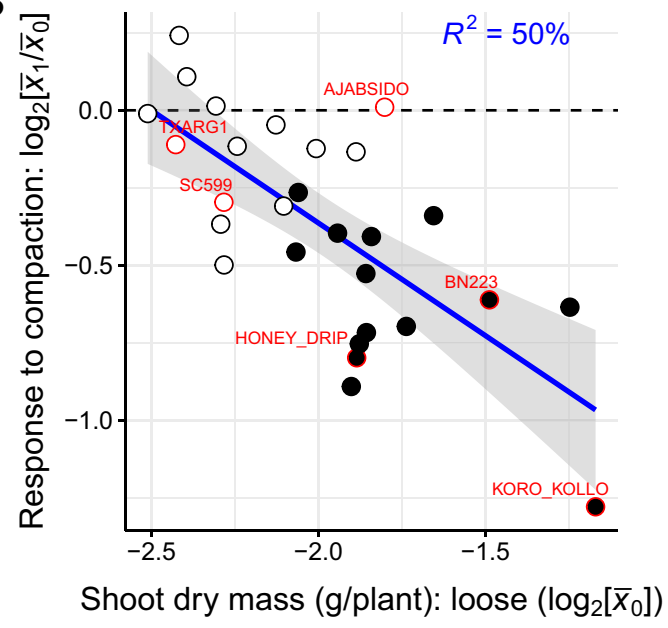

Plastic lines are far below the grey line (solid circles). B Correlation between response to soil compaction and shoot biomass. Phenotypic response to soil compaction (y-axis) is the fold change of the logarithm base two of the ratio of mean value in compacted and loose soil for each genotype giving the plasticity index. Negative numbers indicate biomass is smaller under compacted conditions, and -1 , indicates biomass in compacted conditions was half that of loose conditions. The blue curve with its confidence interval in grey (at 95\%) is the fitted linear regression model between the response and the logarithm base two of the mean value of each genotype under loose conditions 
Table 1 Effect of soil compaction on shoot mass of 3- to 4-week-old plants of sorghum (screening experiment)

\begin{tabular}{|c|c|c|c|c|c|c|c|c|}
\hline \multirow[t]{2}{*}{ Treatment } & \multicolumn{3}{|c|}{ Shoot dry mass (g) } & \multirow[t]{2}{*}{$\mathrm{CV}(\%)$} & \multirow[t]{2}{*}{$n$} & \multicolumn{3}{|c|}{ Factor $\mathrm{R}^{2}(\%)$} \\
\hline & Mean \pm SEM & $\min$ & $\max$ & & & Genotype & Treatment & $\mathrm{G} \times \mathrm{T}$ \\
\hline Loose & $0.259 \pm 0.008$ & 0.035 & 0.857 & 47.7 & 224 & $5.6^{* * *}$ & $88.7 * * *$ & $3.6^{*}$ \\
\hline Compacted & $0.198 \pm 0.005$ & 0.012 & 0.507 & 41 & 224 & & & \\
\hline
\end{tabular}

$\mathrm{SEM}, \min , \max , \mathrm{CV}, n$ : standard error of the mean, minimum, maximum, coefficient of variation; number of observations (pot with 2 plants), respectively

$\mathrm{R}^{2}$ : determination coefficient according to mean square results from two way ANOVA, G $\times$ T: Genotype-by-treatment effect. Significant codes $(P$ value $):<0.001$ ' $* * *$ ’ $0.01-0.05^{\prime} *$ ’

'non-plastic' (white dots). Plastic genotypes had on average $28 \%$ reduced shoot dry mass compared with the responsive ones (Fig. 1). In Fig. 1B, we expressed the plasticity to soil compaction for each genotype using the proposed plasticity index. The plasticity index is 0 when plants are unresponsive, and negative numbers indicate that biomass is smaller under compacted conditions, and -1 , indicates that biomass in compacted conditions was half of measured in loose conditions. Figure 1B shows that response to soil compaction expressed by the plasticity index correlates negatively with shoot biomass in the loose-soil control: The, under controlled conditions, larger-sized genotypes had greater reductions in shoot biomass compared to smaller-sized ones. This association between plant biomass and plasticity was especially clear for 'KORO_KOLLO' and 'TXARG1': 'KORO_ KOLLO' had relatively large plants and expressed the highest shoot biomass reduction, while 'TXARG1' was a non-plastic genotype with a relatively small shoot mass. However, 'AJABSIDO' had relatively large shoot but did not respond to compaction and thereby was an exception to the trend.

Based on experiment 1, we selected six genotypes with varying plasticity and shoot mass (Fig. 1, Supplementary Table S1, Figs. S1, S2). For the highly plastic genotypes, we selected the relatively small 'HONEY_DRIP' (shoots of $0.271 \mathrm{~g}$ in loose soil and $43 \%$ smaller under compacted soil in experiment 1 ) and the relatively large 'KORO_KOLLO' (shoots of $0.444 \mathrm{~g}$ in loose soil and 59\% smaller under compacted soil). For the intermediate responsive genotypes, we chose the relatively small 'SC599' (shoots of $0.205 \mathrm{~g}$ in loose soil and $19 \%$ smaller under compacted soil) and the relatively large 'BN223' (shoots of $0.356 \mathrm{~g}$ in loose soil and $35 \%$ smaller under compacted soil). Finally, for the non-plastic unresponsive (unresponsive) genotypes, we selected the relatively small 'TXARG1' (shoots of $0.186 \mathrm{~g}$ in loose soil and $7 \%$ smaller under compacted soil) and the relatively large 'AJABSIDO' (shoots of $0.287 \mathrm{~g}$ in loose soil and $0 \%$ smaller under compacted soil).

\section{Experiment 2}

In this second experiment, we grew the plants 20 days longer and, consequently, the shoot mass was on average 25 times greater than in experiment 1 . The responsive genotypes in the first experiment were also responsive in the second: 'HONEY_DRIP', 'KORO_KOLLO', and 'BN223'. The only exception was 'AJABSIDO', which was unresponsive in terms of shoot mass in experiment 1 while in experiment 2 it was one of the most responsive lines (reduction in shoot biomass). 'TXARG1' and 'SC599' had the smallest plants and did not respond to soil compaction in either experiment. Importantly, the relationship between plant size and true or apparent plasticity to soil compaction was also strong in the second experiment (Figs. 2, 3, 4, 5; Table 2, Supplementary Fig. S2): the higher the shoot dry mass in loose soil the higher the effect of soil compaction on shoot biomass.

\section{Plasticity of the root and shoot traits}

To summarize the phenotypic plasticity, we plotted a heatmap based on the plasticity index (normalized mean response) for each genotype and trait (Fig. 3). We sorted the traits using a cluster analysis of variables. This yielded four clusters (Fig. 3 top panel, Supplementary Table S2). C1 is mainly made of biomass traits, e.g.: leaf, shoot, stem, and root Dry 

dry mass to soil compaction in 6-week-old plants of six sorghum genotypes. For each genotype, white and black boxes indicate the mean value of shoot dry mass for plants growing in loose and compacted soil. The genotypes are sorted on the $\mathrm{x}$-axis and ranked according to their phenotypic mean under loose conditions, from the largest (left) to the smallest (right). Error bar is the standard error of the mean. Significant results are highlighted in red according to the t-test between loose and compacted conditions. Significance codes ( $P$-value) $:<0.001^{\text {'****'; }}$

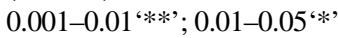

Fig. 2 Response of shoot

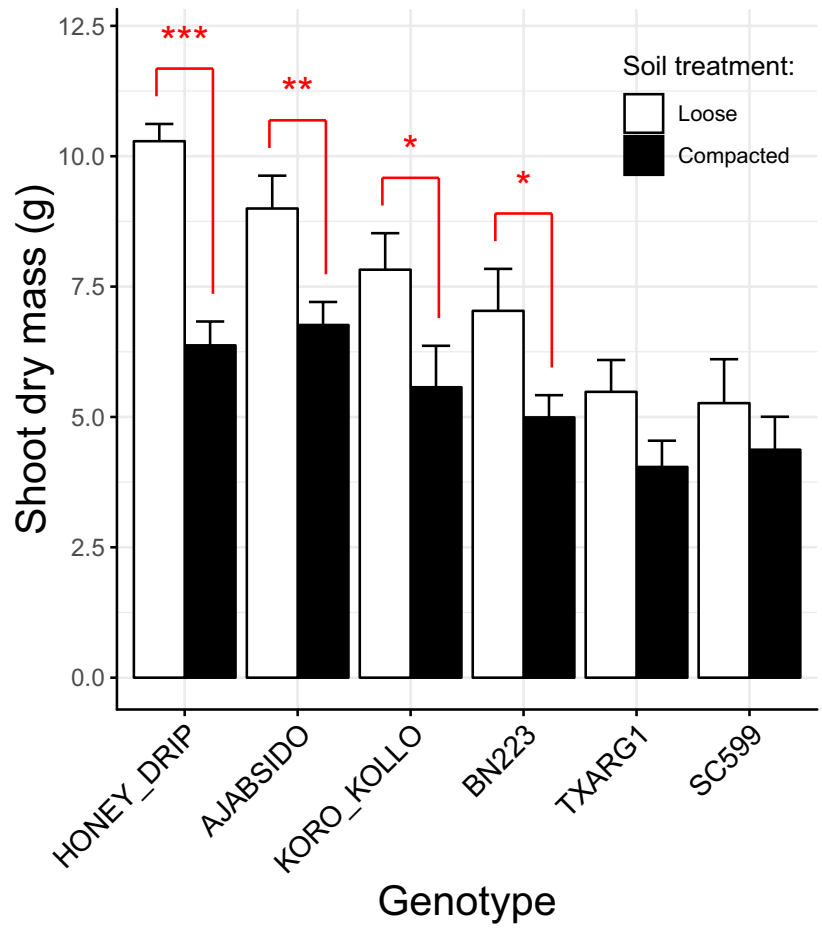

Apparent and true plasticity

Mass. C2 comprised length of coarse roots (diameter $\geq 2.3 \mathrm{~mm}$ ), root diameter, and collar traits (number of nodal roots, root to shoot ratio, collar dry mass, etc.). C3 contained those variables of root length whose diameter was 1.1-1.9 mm. C4 comprised length of roots with diameter less than $1.1 \mathrm{~mm}$, leaf area, and the number of tillers. The average plasticity indices for these clusters were $0.18,-0.34,-0.47$, and -0.48 for $\mathrm{C} 1, \mathrm{C} 2, \mathrm{C} 3$, and $\mathrm{C} 4$, respectively.

Depending on the genotype, most of the traits were affected by soil compaction (as indicated by negative values of plasticity index and dark colors in Fig. 3) and all of them had a significant genotypic effect (Supplementary Table S3). Genotypes were sorted based on their plasticity index by hierarchical clustering (right side). Sorted by their average plasticity index among all the traits, genotypes ranked as follows: (1) 'HONEY_DRIP', (2) 'KORO_KOLLO', (3) 'TXARG1', (4) 'SC599', (5) 'AJABSIDO' and (6) 'BN223' (with $-0.6,-0.5,-0.36,-0.3,-0.3$, and -0.2 , respectively). Cluster $C 4$, comprised of the lengths of roots with diameter classes $\leq 0.2 \mathrm{~mm}$, had the most responsive traits (the darkest colors in the heatmap) with an average plasticity index of $\sim-1.0$.
Based on the ANCOVA (Supplementary Table S4), we plotted to what extent the trait's plasticity was explained by plant biomass (allometric or apparent plasticity), and to what extent it was independent of plant biomass and thereby true plasticity (bottom panel of Fig. 3). Within cluster $\mathrm{C} 4$, the length of very fine roots $($ diameter $<0.1$ ) had a true plasticity effect greater than the apparent plasticity. For example, this trait had both a plasticity index of -1.5 in 'HONEY_DRIP' and 'KORO_KOLLO'.

On average, very fine roots under compacted soils were $54 \%$ shorter than under loose conditions. On the other hand, biomass-related traits, SLA, plant height, root average diameter per plant, and length of thicker roots (diameter $>1.9 \mathrm{~mm}$ ) (clusters $\mathrm{C} 1$ and $\mathrm{C} 2$ ) were less responsive to soil compaction than very fine root traits. $\mathrm{C} 2$ and $\mathrm{C} 1$ were the clusters with relatively high apparent plasticity (explaining 70 and $62 \%$ of the total variance, respectively) and the lower true plasticity (explaining $~ 13$ and $15 \%$ of the total variance, respectively). While C4 and C3 had lower apparent plasticity 


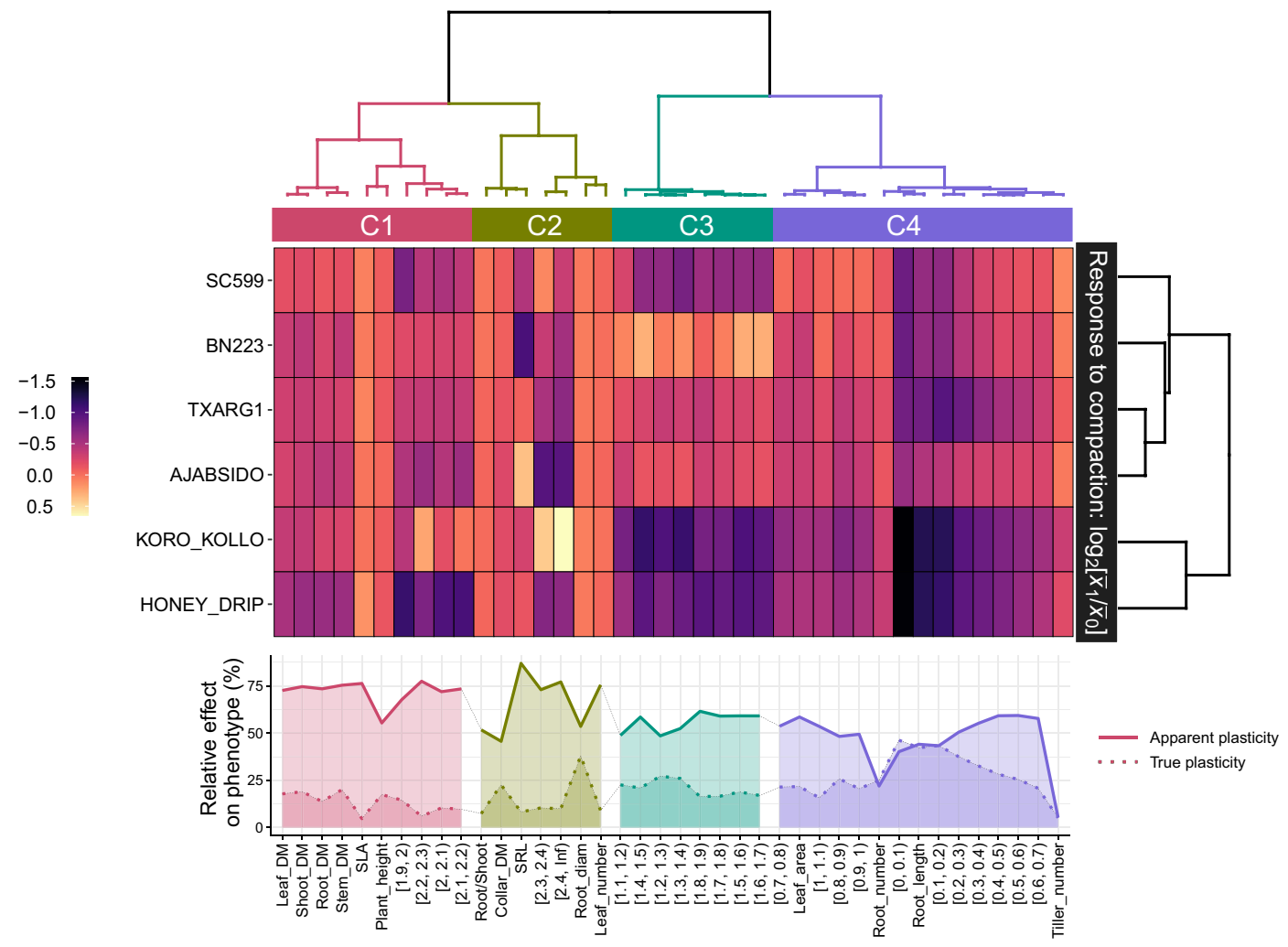

Fig. 3 Response to soil compaction of shoot- and root traits in 6-week-old plants of six sorghum genotypes. The heatmap shows the mean plasticity (degree of response) expressed as the standardized fold change of the logarithm base two of the ratio of mean value in compacted $\left(\bar{x}_{1}\right)$ to that in loose soil $\left(\bar{x}_{0}\right)$ soil for each genotype (rows) and trait (columns). Dark and light colors indicate high and low plasticity, respectively. The relative effect on phenotype of plasticity and apparent plasticity (line graph at the bottom) is based on ANOVA for each trait considering genotype, compaction treatment, plant dry mass (as a covariable) and their interactions as factors. The relative

(explaining 45 and $53 \%$ of the total variance, respectively) and higher true plasticity (explaining $~ 28$ and $21 \%$ of the total variance, respectively; Fig. 3; Supplementary Table S4).

\section{Root/shoot ratios}

Root biomass was correlated with shoot biomass, root/shoot ratios, leaf area, and root length both in loose ( $r>75 \%$; Supplementary Table S5) and compacted soil ( $r>75 \%$; Supplementary Table S6). Under compaction, root biomass was on average reduced by $35 \%$ compared to the loose control. effect is calculated by using the mean squares of each of these factors. Thus, plasticity is the sum of the importance of treatment and treatment-by-genotype interaction effects; apparent plasticity (allometric effect) is the sum of the importance of plant dry mass and all their interactions with treatment, genotype, and genotype-by-treatment interaction effects. Traits are sorted according to a variable clustering located on the top of the heatmap. Genotypes are sorted according to hierarchical clustering of their response to soil strength, displayed on the right side of the heatmap

Genotypes differed in root biomass but the $\mathrm{G} \times \mathrm{T}$ interaction was not significant (Supplementary Table S3).

Compaction reduced root/shoot ratios by $11 \%$ on average and the largest proportion of variation was explained by genotypic effect (Supplementary Table S3). The log-log (allometric) relationship between shoot and root biomass across replicates and genotypes (Table 3) was significantly different between soil conditions. For every one percent change in shoot mass, there was a 1.37 and $1.7 \%$ change in root mass for compacted and loose soil treatments, respectively (see slopes in Table 3). 


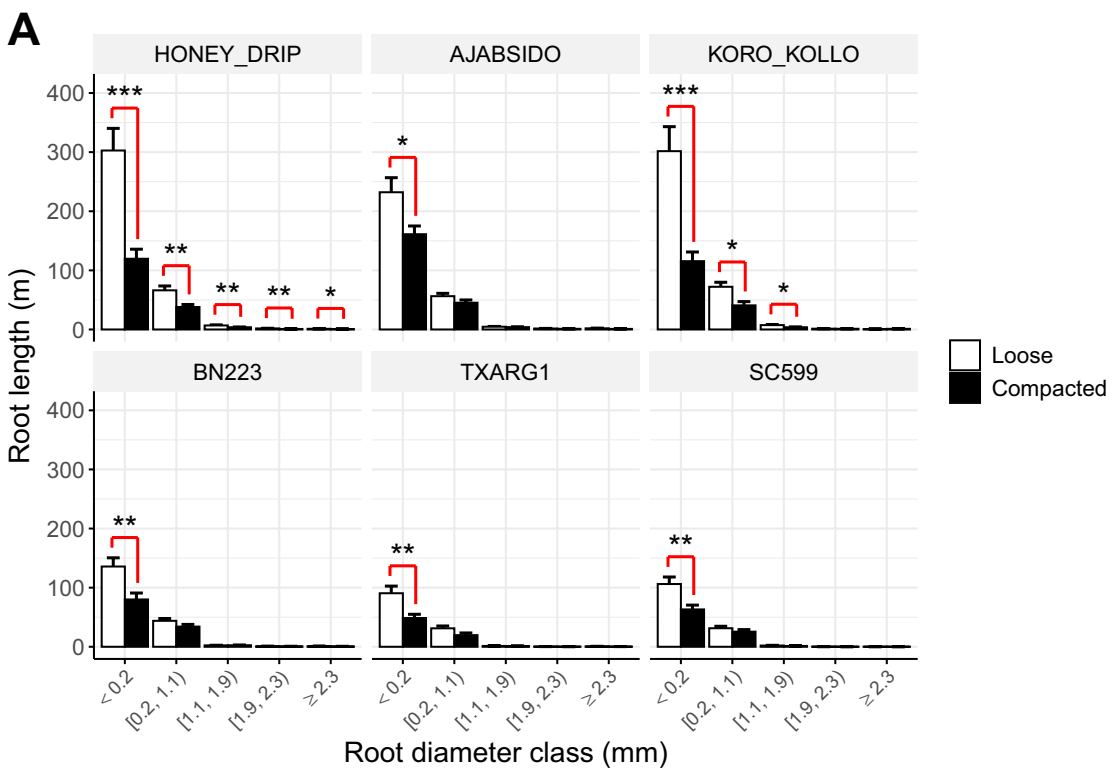

B

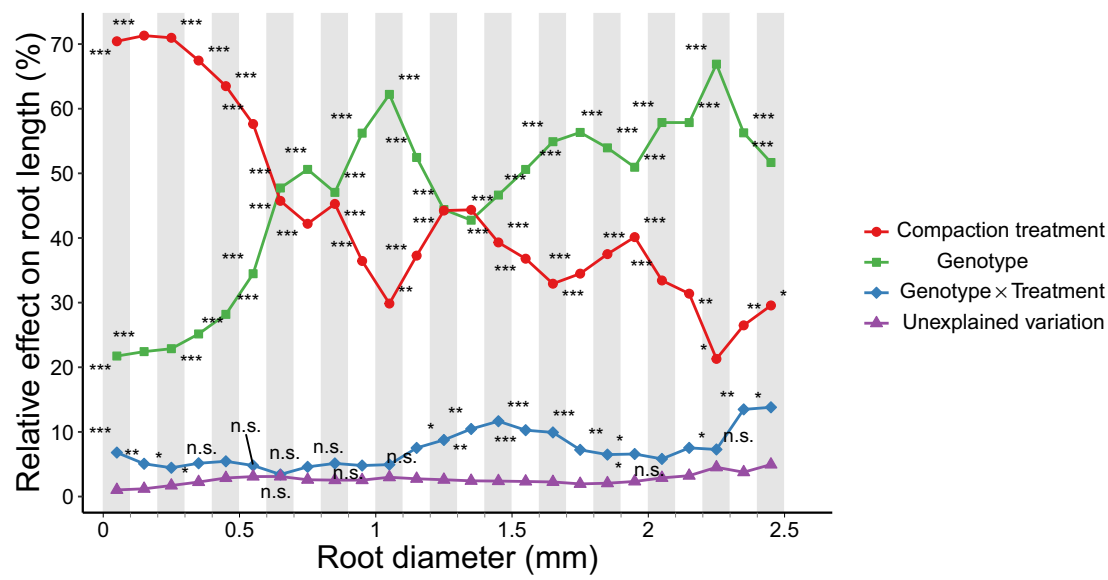

Fig. 4 Response of root length to soil compaction in 6-weekold plants of six sorghum genotypes. A Distribution of root length by root diameter class. The root length was recorded in five root diameter classes ranging from 0 to $2.5 \mathrm{~mm}$. These five classes were based on cluster analysis (see Fig. 3). Genotypes are sorted according to Fig. 1. White and black boxes: mean of root length $(\mathrm{mm})$ for each diameter class in loose and compacted soil conditions, respectively. Error bar: standard error of the mean. The significant results are highlighted

\section{Length of fine and coarse roots}

Root length (Table 4) ranged from $383 \mathrm{~m}$ of 'KORO_KOLLO' under loose soil to only $70 \mathrm{~m}$ of 'TXARG1' in compacted soil. Soil compaction reduced root length of all genotypes (46\% of in red according to the t-test between loose and compacted conditions. B Relative effect of genotype and soil compaction treatment on root length for each diameter class. Root length in 25 root diameter classes ranging from 0 to $2.5 \mathrm{~mm}$. Diameter classes are indicated as grey or white vertical bands. The relative effect is calculated by using the mean squares of each of these factors. Significance codes $(P$-value $):<0.001^{\text {'****; }}$;

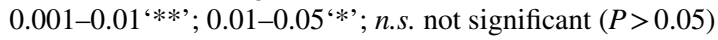

reduction on average). For example, roots of ' $\mathrm{KORO}$ KOLLO' and 'HONEY_DRIP' were almost 58\% shorter under compacted than in loose soil conditions. Even unresponsive shoot genotypes to compaction such as 'SC599' had an important reduction in root length (35\% shorter roots under compacted soil). 
Fig. 5 Response of leaf area to soil compaction over time in 6-week-old plants of six sorghum genotypes. A Estimated leaf area over time for the six selected genotypes growing in loose and compacted soils. The measurements were done twice a week yielding in total 13 date points (days after transplanting). Genotypes are sorted according to their leaf area at harvest under loose conditions (from the largest to the smallest): 'HONEY_DRIP', 'AJABSIDO', 'KORO_KOLLO', 'BN223', 'TXARG1', and 'SC599'. White and black circles: mean of estimated leaf area $\left(\mathrm{cm}^{2}\right)$ for loose and compacted soil conditions, respectively. Error bar: standard error of the mean. The significant results are highlighted in red according to the t-test between loose and compacted conditions. B Relative effect of genotype and soil compaction treatment on leaf area for each measurement date. The relative effect is calculated by using the mean squares of each of these factors. $\mathbf{C}$ Variation over time of the leaf area response to soil compaction for each genotype. The response is the fold change of the logarithm base two of the ratio of mean value in compacted and loose soil for each genotype and date point. Significance codes ( $P$-value): $<0.001^{\text {'***'; }}$ 0.001-0.01 ‘**'; 0.01$0.05^{\prime *}$; ; n.s. not significant $(P>0.05)$
A

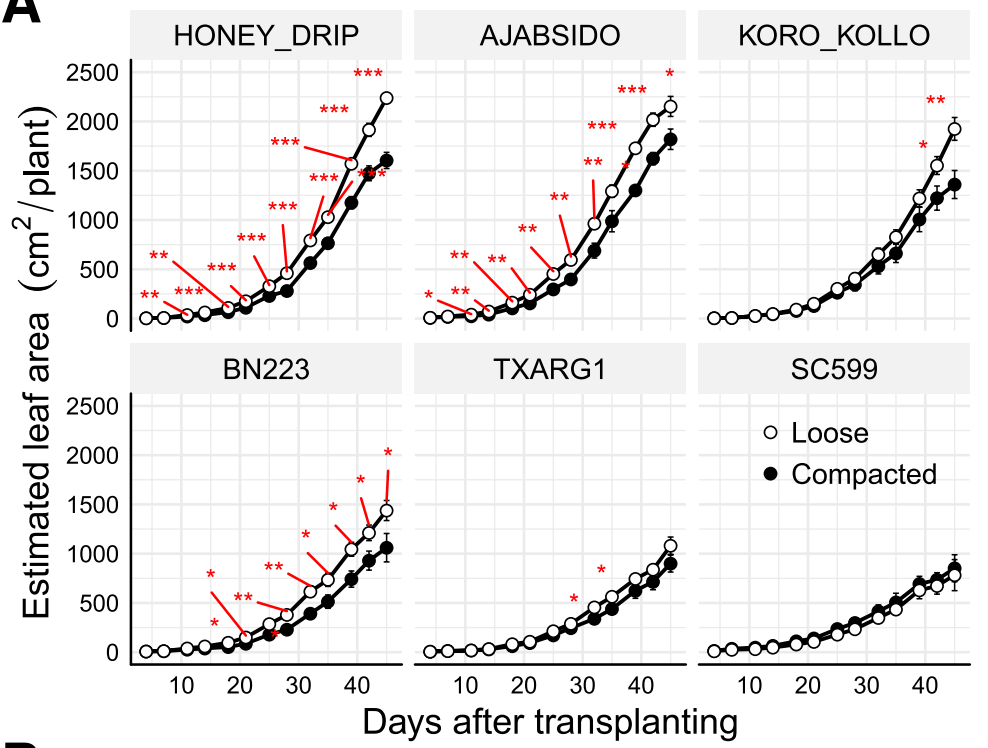

B

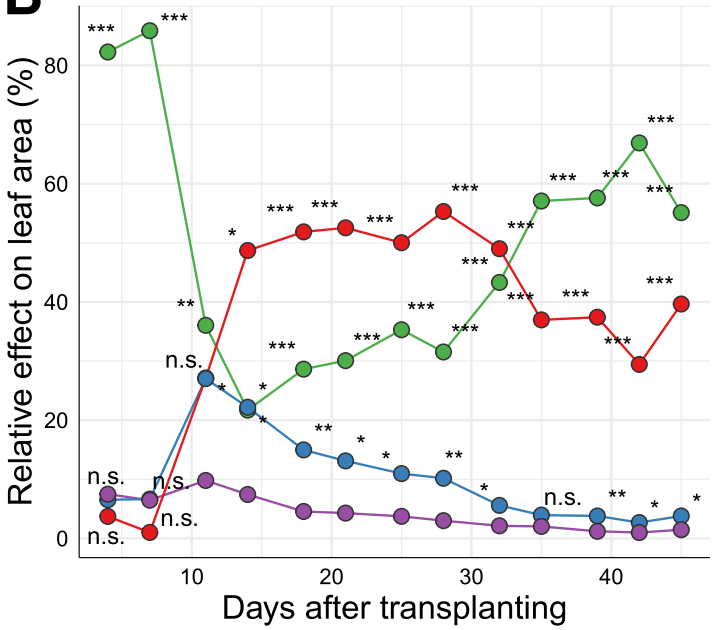

- Compaction treatment

- Genotype

- Genotype $\times$ Treatment

- Unexplained variation

C

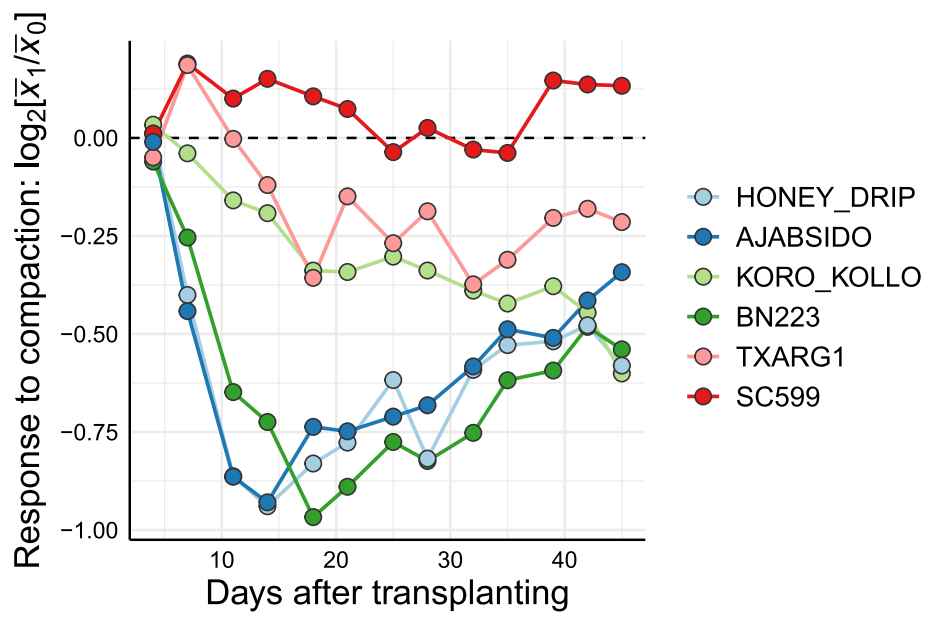


Table 2 Genotypic diversity of plant dry mass (g) in loose and compacted soil

\begin{tabular}{|c|c|c|c|c|}
\hline \multirow[t]{2}{*}{ Genotype } & \multicolumn{2}{|l|}{ Loose } & Compacted & \multirow{2}{*}{$\begin{array}{l}\text { Within- } \\
\text { genotype } \\
\text { treatment } \\
\text { effect }^{2}\end{array}$} \\
\hline & Mean \pm SEI & & Mean \pm SEM & \\
\hline $\begin{array}{l}\text { HONEY }_{-} \\
\text {DRIP }\end{array}$ & $13.1 \pm 0.58$ & $\mathbf{a}$ & $7.8 \pm 0.63 \quad \mathbf{a b}$ & $* * *$ \\
\hline AJABSIDO & $12.9 \pm 0.95$ & $\mathbf{a}$ & $9.3 \pm 0.73 \quad \mathbf{a}$ & $* *$ \\
\hline $\begin{array}{l}\text { KORO_- }_{\text {KOLLO }} \\
\text { KOL }\end{array}$ & $10.7 \pm 1.05$ & $\mathbf{a b}$ & $7.8 \pm 1.24 \quad \mathbf{a b}$ & n.s. \\
\hline BN223 & $8.7 \pm 1.07$ & bc & $6.2 \pm 0.58 \quad \mathbf{a b}$ & n.s. \\
\hline TXARG1 & $6.6 \pm 0.77$ & c & $4.7 \pm 0.61 \quad$ b & n.s. \\
\hline SC599 & $6.2 \pm 1.02$ & c & $5.0 \pm 0.71 \quad$ b & n.s. \\
\hline
\end{tabular}

${ }^{1}$ Different letters indicate means \pm standard error of the mean (SEM) with statistically significant differences among genotypes according to Fisher's least significant difference test $(P<0.05)$.

${ }^{2}$ The significant codes are according to the t-test between the means under loose and compacted conditions for each geno-

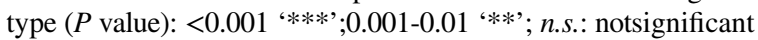
$(P>0.05)$.
Additionally, total root length was significantly correlated with plant biomass ( $r=72$ and $83 \%$ in loose and compacted soil, respectively) and $38 \%$ of the observed phenotypic variation in root length was explained by the variation in plant biomass, and the slopes of the regression depended significantly on genotype and treatment (see for ANCOVA in Supplementary Table S4).

We split root length into five root diameter classes (Fig. 3 for cluster analysis; Fig. 4 for root length). The classes with smaller diameters had much greater root lengths than those with thicker diameters (Fig. 4A). We refer to "fine roots" as the class of roots with diameters $\leq 0.2 \mathrm{~mm}$. Unlike leaf area development, all the genotypes responded to the soil compaction treatment with a reduced root length in one or more root diameter classes: especially, all genotypes had reduced length in the fine root class in response to soil compaction. Genotypes 'HONEY_DRIP' and 'KORO_KOLLO', had large shoot dry mass response, also the greatest root length decrease

Table 3 Relative contribution of soil treatment and shoot biomass to the variation of root biomass

\begin{tabular}{|c|c|c|c|c|c|c|}
\hline \multicolumn{4}{|c|}{ Regression coefficients for each treatment } & \multicolumn{3}{|c|}{ Effects on root dry mass $(\%)^{2}$} \\
\hline Treatment (T) & $\mathrm{R}^{2}(\%)^{1}$ & intercept & slope & $\mathrm{T}$ & Shoot_DM & $\mathrm{T} \times$ Shoot_DM \\
\hline Loose & 85.4 & -3.07 & 1.70 & $8.0 * * *$ & $90.9 * * *$ & $1.0^{*}$ \\
\hline Compacted & 76.6 & -2.39 & 1.37 & & & \\
\hline
\end{tabular}

${ }^{1} \mathrm{R}^{2}$ : determination coefficient according to linear regression model within each treatment: $\ln ($ Root_DM $)=$ intercept + slope $\times \ln ($ Shoot_DM)

${ }^{2}$ Determination coefficient according to mean square results from ANCOVA

Table 4 Genotypic diversity of total root length $(\mathrm{cm})$ in loose and compacted soil

\begin{tabular}{|c|c|c|c|c|c|}
\hline \multirow[t]{2}{*}{ Genotype } & \multicolumn{2}{|l|}{ Loose } & \multicolumn{2}{|l|}{ Compacted } & \multirow{2}{*}{$\begin{array}{l}\text { Within-genotype } \\
\text { treatment effect }\end{array}$} \\
\hline & Mean \pm SEM $^{1}$ & & Mean \pm SEM & & \\
\hline KORO_KOLLO & $38329.7 \pm 4976$ & $\mathbf{a}$ & $16239.1 \pm 2253$ & $\mathbf{a b}$ & $* *$ \\
\hline HONEY_DRIP & $37877.2 \pm 4588$ & $\mathbf{a}$ & $16299.7 \pm 2089$ & $\mathbf{a b}$ & $* *$ \\
\hline AJABSIDO & $29674.6 \pm 2891$ & $\mathbf{a b}$ & $21251.0 \pm 1847$ & $\mathbf{a}$ & $*$ \\
\hline BN223 & $18374.1 \pm 1882$ & bc & $11808.5 \pm 1411$ & bc & $*$ \\
\hline SC599 & $14010.4 \pm 1512$ & c & $9046.5 \pm 1047$ & c & $*$ \\
\hline TXARG1 & $12416.1 \pm 1628$ & c & $7012.9 \pm 1016$ & c & * \\
\hline
\end{tabular}

$\overline{{ }^{1} \text { Different letters indicate means } \pm \text { standard error of the mean (SEM) with statistically significant differences among genotypes }}$ according to Fisher's least significant difference test $(P<0.05)$ within each soil treatment level.

${ }^{2}$ The significant codes are according to the t-test between loose and compacted conditions within each genotype ( $P$ value): $0.001-$ 0.01 '**', 0.01-0.05 '*' 
under compacted soil: about $57-58 \%$ shorter roots, and showed responses to soil compaction for almost all the root diameter classes. On the other hand, the smaller genotypes, 'BN223', 'TXARG1' and 'SC599', had significant effects on fine roots only. This was also true for the larger 'AJABSIDO'. Overall, the plant biomass explained 33-38\% of the phenotypic variation of the fine root length. Root length of thicker roots correlated stronger to plant biomass: plant biomass explained $65 \%$ or more of the phenotypic variation in the length of roots with diameters $>2 \mathrm{~mm}$ (Supplementary Table S4).

Figure 4B shows the relative effect of soil compaction and genotype on the root length for each diameter class. Treatment had a relative effect of 50-70\% for roots whose diameters were less than $0.6 \mathrm{~mm}$. In the case of fine roots, this effect explained about $70 \%$ of the variation in root length.

The second most important explanatory variable was genotype, especially for thicker roots. This interaction was significant in almost all the diameter classes ranging between 5 and $15 \%$ of the total variation. Similarly, this interaction explained $\sim 8 \%$ of the total variation in root length.

\section{Leaf area development}

To track the effect of soil compaction on the development of shoot, we estimated leaf area development non-destructively based on color images of our plants. Green pixel count was validated against measured leaf area at harvest $\left(\mathrm{R}^{2}=99 \%, \mathrm{RMSE}=156.3\right.$ Supplementary Fig. S3). Figure 5A shows the increase in estimated leaf area over time based on this validation. Genotypes had different total leaf areas at harvest in loose soil (from the largest to the smallest): 'HONEY_DRIP', 'AJABSIDO', 'KORO_KOLLO', 'BN223', 'TXARG1', and 'SC599'. The four genotypes with a significant effect on shoot dry mass (Fig. 2) also responded to soil compaction in terms of leaf area. In addition to being the biggest genotypes in terms of leaf area and shoot dry mass, 'KORO_ KOLLO' and 'HONEY_DRIP' had the largest reduction in leaf area (32 and 29\% smaller values under compacted soils; Fig. 5A) and shoot biomass (28 and $38 \%$ smaller values under compacted soils; Fig. 2).
Leaf area variation was mainly influenced by genotypic differences during the first days of growth explaining almost $80 \%$ of the total variation. The treatment effects on larger genotypes became evident during the second week after transplanting (Fig. 5A, B). At this time, the treatment became the more important source of variation explaining almost 50\% of the variation in leaf area. Genotype became again the most explanatory factor during later stages.

As in Figs. 1 and 2, larger genotypes had the higher leaf area responses (Fig. 5C). 'KORO_ KOLLO' and 'TXARG1' only had significant treatment effects 30 days after transplanting. For these two genotypes, the treatment effect accelerated almost constantly until harvest time (Fig. 5C). On the other hand, Fig. 5B and $\mathrm{C}$ show that the degree of leaf area response decreased with time from 20 days after transplanting onward, specifically for 'AJABSIDO', 'BN223' and 'HONEY_DRIP'. On the contrary, 'SC599' did not respond to compaction and consequently, its plasticity index was very close to zero (Fig. 5C).

\section{Discussion}

Overall, compaction reduced plant size but large variation among genotypes existed. Additionally, the plasticity to compaction was correlated to plant size. Finally, we found that the $\mathrm{G} \times \mathrm{T}$ explained a small portion of the observed variation next to the effect of plant biomass. We have observed genetic variation in both above- and belowground plasticity to soil compaction. Some of this variation may be explained by plant size (allometric), and thereby a form of apparent plasticity (Correa et al. 2019; Weiner 2004). Phenotypic plasticity varied among genotypes and depended on biomass, with larger genotypes responding at earlier developmental stages and more intensely. We observed not only genetic variation for phenotypic response/plasticity in shoot size-related parameters, but also for plasticity in various root traits. Although all traits were correlated to plant size, especially the number of nodal roots and fine root length had strong true plasticity. Larger trials, however, are necessary to determine the heritability of true plasticity to soil compaction of those traits. 
Responses associated with plant size

In the second experiment, we grew the plants 20 days longer in bigger pots and, consequently, the shoot biomass was on average 25 times higher than in experiment 1. Plastic genotypes in the screening also were plastic in experiment 2 but shoot dry mass was sometimes inconsistent between experiments 1 and 2 (Fig. 2; Supplementary Fig. S2) At harvest, the roots of experiment 2 were able to colonize the entire pot, which may have reduced the impact of compaction for a small proportion of roots that were growing in areas with decreased penetration resistance, e.g. at the pot walls boundaries. Despite this, it is important to note that the relationship between plant size and response to soil compaction was also observed in both experiments (Figs. 1, 2, 3, 4, 5): the higher the shoot dry mass in loose soil the higher the effect of soil compaction on shoot biomass.

In general, larger genotypes were more responsive than those genotypes with smaller plants (Figs. 1, 2, 3, 4, 5). Selecting genotypes with different degrees of response had as a consequence that different plant sizes were also co-selected.

It is difficult to distinguish true or apparent plasticity because root to shoot ratio decreases as soil density increases and is correlated with plant mass. It is known that smaller or younger plants generally have comparatively greater root/shoot ratios (McConnaughay and Coleman 1999; Weiner 2004). On the contrary, we found that plants under compaction had lower root/shoot ratios despite being smaller than plants in loose soils. Additionally, the number of leaves on the main axis was not significantly affected by compaction. The log-log relationship between shoot and root biomass (Table 3) showed soil treatments had different slopes indicating different allocation patterns: an indication for true plasticity (Reich 2002). The slopes mean that a one percent decrease in shoot mass was associated with a 1.37 and $1.7 \%$ decrease in root mass for compacted and loose soil treatments, respectively. Therefore, plants growing in compacted soil have proportionally less root than shoot mass compared with non-impeded plants. This decrease in root/shoot ratios is accentuated by the fact that the plants are smaller and that smaller plants normally have increased root/shoot ratios. A decreased root/shoot ratio means that genotypes showed different biomass partitioning in favor of shoots under compacted soil.
Root responses

Almost $75 \%$ of the total root length was represented by fine roots whose diameters were less than $0.2 \mathrm{~mm}$. Fine roots were not only the most responsive component of the total length of the root to soil compaction (Figs. 3, 4) but also the most responsive trait (Fig. 5; Supplementary Table S3). Given their functional importance, we may assume that the reduction of fine root length has a great impact on root functioning. Due to their greater surface area per unit volume, fine roots are the principal pathway for nutrient and water uptake (Comas et al. 2013; Eissenstat 1992). Additionally, they have significantly higher rates of respiration, associated with higher $\mathrm{N}$ concentrations, compared with thicker roots (Eissenstat and Yanai 1997; Pregitzer et al. 1998) and a relatively short lifespan, rapid turnover, and quick decomposition (Jackson et al. 1997). Although fine root production is likely mechanically impeded in compacted soils, they may also be hampered by the low availability of soil resources such as $\mathrm{N}$ and oxygen (Bengough et al. 2011; Håkansson et al. 1988; Passioura 2002; Tubeileh et al. 2003). Based on that, the observed reduction of fine roots may be related to an optimization strategy of carbon and/or soil resources and as such adaptive plasticity. Plastic and tolerant genotypes could avoid producing fine roots not only because of their high cost under impeded conditions but also because they may be less efficient under compaction. Plants likely have mechanisms to compensate for a shorter root system by increasing the root uptake efficiency especially in those genotypes with unresponsive shoots. Further studies are needed to assess how greater resource acquisition efficiency can compensate for the loss of fine root length.

\section{Shoot responses}

A common response to soil compaction is the reduction in shoot mass and leaf area of plants (Beemster and Masle 1996; Grzesiak et al. 2014; Masle and Passioura 1987). The same was found in our experiments (Tables 1, 2; Figs. 1, 2, 5). The soil strength levels applied in this experiment $(>3 \mathrm{MPa})$ are considered highly limiting for root growth (Bengough et al. 2011; Passioura 2002; Pierce et al. 1983) and affected shoot growth of plants younger than 4 weeks (Figs. 1, 2; Supplementary Fig. S2). 
Shoot plasticity to soil compaction varied among genotypes (Figs. 1, 2, 5), but we did not find a clear association between observed shoot phenotype and the genotype's origin or breeding status (ANOVA: $P$-value $>0.05)$. The genotypic variation in shoot responses to soil compaction was correlated to plant size under loose soil (Figs. 1, 2). Hence, genotypes with larger plants under loose soil had greater reductions in leaf area than smaller sized genotypes under soil compaction.

The effects on shoots were evident from the second week after transplanting onward (Fig. 5). This early response is in agreement with previous observations on seedlings and young plants of wheat and barley growing in compacted soil (Goss and Russell 1980; Masle 1992; Masle and Passioura 1987; Rebetzke et al. 2014). The early response may be a factor to be considered as early vigor is key to the establishment and survival of seedlings especially under conditions of topsoil compaction. The increased soil strength by soil crusting, i.e. a formation of a seal at the soil surface, affects negatively both seedling emergence and establishment (Awadhwal and Thierstein 1985; Nortjé et al. 2012). Thus, seedling establishment of highly responsive lines may be severely reduced and may need to be compensated for by higher seeding rates. This is especially relevant for sorghum since it is said to be sensitive to crusting (Awadhwal and Thierstein 1985).

\section{Genetic diversity in response to soil compaction}

Genetic diversity in the plasticity of plants to soil compaction has been documented in other studies (Arvidsson and Håkansson 2014; Colombi and Walter 2017; Grzesiak et al. 2014; Materechera et al. 1992; Rebetzke et al. 2014). If plasticity is adaptive and has a clear genetic basis, it can be useful for breeding. Therefore, the study of both genetic variation and the contribution to crop yield of these root responses is essential. Sorghum has wide genotypic diversity (e.g. Sinha and Kumaravadivel 2016). By using varieties with different geographical and genetic origin and breeding status, we expect that our panel represented this diversity (Supplementary Table S1). We found that the genotypic effect accounted for a large portion of the observed phenotypic variation (Tables 1, 2, 3; Supplementary Tables S4, S5). We expected that different sorghum genotypes differ in their plasticity to soil compaction, and indeed found a significant $\mathrm{G} \times \mathrm{T}$ for several traits, notably root length. Other traits with significant $\mathrm{G} \times \mathrm{T}$ were the number of nodal roots and tillers. In our second experiment, roots were more affected than shoots (Fig. 3). For example, the observed reduction in both root length and biomass in response to soil compaction was approximately 50 and $35 \%$, respectively. While the reduction observed in terms of shoot biomass and leaf area was less than $30 \%$. Therefore, sorghum genotypes differ in their plasticity to soil compaction $(\mathrm{G} \times \mathrm{T})$ and this might be exploited in future breeding programs.

Unresponsive lines growing in compacted soil have a relatively lower root/shoot ratio and a smaller proportion of fine roots. A reduced proportion of fine roots could be a sign of 'damage' but may be true adaptive plasticity if reduced investment into fine roots is accompanied by increased investment into other resource acquisition strategies resulting in greater uptake efficiency. However, more studies are needed to establish whether greater root absorption efficiency would compensate for the reduction in fine root length and its relationship with yield. Maintaining shoot growth relatively stable while the root modifies its structure can be an important adaptation mechanism to soil compaction.

The degree of response to soil compaction was correlated with plant biomass (Tables 1, 2, 3; Figs. 1, 2, 3, 4, 5). In general, larger genotypes such as 'KORO_KOLLO' and 'HONEY_DRIP' were the more plastic and displayed the higher and earlier response to soil compaction in terms of length of fine roots and leaf area than smaller plant genotypes such as 'TXARG1' and 'SC599'. On the other hand, 'AJABSIDO', a "drought-tolerant landrace" from Sudan (Supplementary Table S1), was a genotype that was relatively large and had intermediate plasticity. Shoot and root biomass of 'AJABSIDO' in compacted soil were reduced by 25 and $35 \%$ compared to the loose control, respectively. We know that penetration resistance increases as soil water potential decreases (Bengough et al. 2011; Whalley et al. 2005). It is likely that tolerance to compaction and drought evolved together and share some physiological or structural mechanisms of the plant to adapt to higher soil resistance conditions. For example, it has been observed that some maize and triticale genotypes that were tolerant to soil compaction were also drought tolerant (Grzesiak et al. 2014). 'AJABSIDO' 
may thus be an interesting "ideotype" for both compaction and drought tolerance.

In general the genotypes of larger plants are proportionally more affected than smaller ones by soil compaction. One might conclude that tolerance to soil compaction cannot be exploited if it is associated with overall reduced vigor. However, high yields can be obtained using less vigorous genotypes by growing them at higher planting densities, assuming harvest index of the less vigorous lines is not reduced. We suggest that the extreme tolerance of 'TXARG1' and 'SC599' may still be exploited in breeding.

Root system plasticity to soil compaction is complex and involves dynamic changes and several interactions among root traits that were not addressed in our study. For example, greater production of thicker and steeper roots may be of advantage (Correa et al. 2019). This allows a better soil exploration that could be even more efficient if the roots are able to find those paths and patches with the least resistance to penetration. In those soil patches, some resources, such as oxygen and nitrogen, may be more available than in their surroundings. The proliferation of roots in these patches can be a way to compensate for the loss of root length.

\section{Conclusions}

As long as the plasticity is adaptive and has a clear genetic basis, it will be useful for breeding. Sorghum genotypes differ in plasticity to soil compaction $(\mathrm{G} \times \mathrm{T})$ and, indeed, we found a significant $\mathrm{G} \times \mathrm{T}$ for several traits, particularly root length. This genetic diversity in plasticity could be exploited in future breeding programs. However, plant size explained a larger proportion of the trait variation than $\mathrm{G} \times \mathrm{T}$, which can pose challenges in plasticity-based breeding and requires further research, especially if the tolerant but smaller sized genotypes can have high yields when grown at greater plant densities. To the best of our knowledge, this is the first study that illustrates how the phenotypic responses to soil compaction correlate with the potential plant size of a genotype in sorghum. Finally, the observed phenotypic changes in response to soil compaction are complex, both apparent plasticity (allometry) and plasticity are involved but apparent and true plasticity are distinguishable and measureable across genotypes. The association between tolerance and plant size can pose challenges in achieving high yields through breeding and requires further research. In general, root traits were more plastic than shoot traits. Plasticity was expressed foremost in nodal root number and fine roots, whereas thick root length was much less affected and more correlated with plant biomass. Fine roots were the most plastic component of root total length and the most plastic overall plant traits.

As long as the plasticity is adaptive and has a clear genetic basis, it will be useful for breeding. Sorghum genotypes differ in plasticity to soil compaction $(\mathrm{G} \times \mathrm{T})$ and, indeed, we found a significant $\mathrm{G} \times \mathrm{T}$ for several traits, particularly root length. This genetic diversity in plasticity could be exploited in future breeding programs. However, plant size explained a larger proportion of the trait variation than $\mathrm{G} \times \mathrm{T}$, which can pose challenges in plasticity-based breeding and requires further research, especially if the tolerant but smaller sized genotypes can have high yields when grown at greater plant densities. To the best of our knowledge, this is the first study that illustrates how the phenotypic responses to soil compaction correlate with the potential plant size of a genotype in sorghum. Finally, the observed phenotypic changes in response to soil compaction are complex, both apparent plasticity (allometry) and plasticity are involved but apparent and true plasticity are distinguishable and measureable across genotypes. The association between tolerance and plant size can pose challenges in achieving high yields through breeding and requires further research. In general, root traits were more plastic than shoot traits. Plasticity was expressed foremost in nodal root number and fine roots, whereas thick root length was much less affected and more correlated with plant biomass. Fine roots were the most plastic component of root total length and the most plastic overall plant traits.

Plant responses to soil compaction can be explained to a large degree by allometry that is the responsive and unresponsive genotypes are relatively small and large, respectively. Nevertheless, true plasticity (sizeindependent responses) was observed especially for the number of nodal roots and root length of fine roots, but also for biomass allocation patterns.

'AJABSIDO' was a genotype that was relatively large and had intermediate plasticity responses showing the best growth under compacted conditions and therefore, may serve as an 'ideotype' in breeding to mitigate the constraints of compacted soils. 
Acknowledgements We thank Professor Mitch Tuinstra (Purdue University, IN, USA) for selecting and providing a subset of sorghum genotypes from a larger diversity panel. We also thank Fabio Fiorani (Forschungszentrum Jülich, Germany) for constructive comments as third-party reviewer.

Funding Open Access funding enabled and organized by Projekt DEAL. These studies were institutionally funded by the Helmholtz Association, Germany.

\section{Declarations}

Conflict of interest The authors declare no conflict of interest.

Open Access This article is licensed under a Creative Commons Attribution 4.0 International License, which permits use, sharing, adaptation, distribution and reproduction in any medium or format, as long as you give appropriate credit to the original author(s) and the source, provide a link to the Creative Commons licence, and indicate if changes were made. The images or other third party material in this article are included in the article's Creative Commons licence, unless indicated otherwise in a credit line to the material. If material is not included in the article's Creative Commons licence and your intended use is not permitted by statutory regulation or exceeds the permitted use, you will need to obtain permission directly from the copyright holder. To view a copy of this licence, visit http://creativecommons.org/licenses/by/4.0/.

\section{References}

Arvidsson J (1999) Nutrient uptake and growth of barley as affected by soil compaction. Plant Soil 208:9-19. https:// doi.org/10.1023/A:1004484518652

Arvidsson J, Håkansson I (2014) Response of different crops to soil compaction-Short-term effects in Swedish field experiments. Soil Tillage Res 138:56-63. https://doi.org/ 10.1016/j.still.2013.12.006

Atkinson JA, Hawkesford MJ, Whalley WR, Zhou H, Mooney SJ (2020) Soil strength influences wheat root interactions with soil macropores. Plant Cell Environ 43:235-245. https://doi.org/10.1111/pce.13659

Awadhwal NK, Thierstein GE (1985) Soil crust and its impact on crop establishment: A review. Soil till Res 5:289-302. https://doi.org/10.1016/0167-1987(85)90021-2

Barken LR, Bøsrresen T, Njøss A (1987) Effect of soil compaction by tractor traffic on soil structure, denitrification, and yield of wheat (Triticum aestivum L.). Eur J Soil Sci 38:541-552. https://doi.org/10.1111/j.1365-2389.1987. tb02289.x

Beemster GTS, Masle J (1996) Effects of soil resistance to root penetration on leaf expansion in wheat (Triticum aestivum L.): composition, number and size of epidermal cells in mature blades. J Exp Bot 47:1651-1662. https://doi.org/ 10.1093/jxb/47.11.1651

Bengough AG, Mullins CE (1990) Mechanical impedance to root growth: a review of experimental techniques and root growth responses. Eur J Soil Sci 41:341-358. https://doi.org/10.1111/j.1365-2389.1990.tb00070.x

Bengough AG, McKenzie BM, Hallett PD, Valentine TA (2011) Root elongation, water stress, and mechanical impedance: a review of limiting stresses and beneficial root tip traits. J Exp Bot 62:59-68. https://doi.org/10. 1093/jxb/erq350

Bingham IJ, Bengough AG, Rees RM (2010) Soil compaction-N interactions in barley: Root growth and tissue composition. Soil till Res 106:241-246. https://doi.org/ 10.1016/j.still.2009.10.008

Blum A, Sullivan CY (1997) The effect of plant size on wheat response to agents of drought stress. I. Root Drying Aust J Plant Physiol 24:35-41. https://doi.org/10. 1071/PP96022

Blum A, Sullivan CY, Nguyen HT (1997) The effect of plant size on wheat response to agents of drought stress. II. Water deficit, heat and ABA. Aust J Plant Physiol 24:4348. https://doi.org/10.1071/PP96023

Bradshaw AD (1965) Evolutionary significance of phenotypic plasticity in plants. Adv Genet 13:115-155

Chavent M, Kuentz V, Liquet B, Jerome Saracco J (2017) ClustOfVar: clustering of variables. $\mathrm{R}$ package version 1.1. https://CRAN.R-project.org/package=Clust OfVar. Accessed 24 Oct 2019

Coelho Filho MA, Colebrook EH, Lloyd DPA, Webster CP, Mooney SJ, Phillips AL, Hedden P, Whalley WR (2013) The involvement of gibberellin signalling in the effect of soil resistance to root penetration on leaf elongation and tiller number in wheat. Plant Soil 371:81-94. https://doi. org/10.1007/s11104-013-1662-8

Colombi T, Walter A (2017) Genetic diversity under soil compaction in wheat: Root number as a promising trait for early plant vigor. Front Plant Sci 8:420. https://doi.org/10. 3389/fpls.2017.00420

Comas LH, Becker SR, Cruz VMV, Byrne PF, Dierig DA (2013) Root traits contributing to plant productivity under drought. Front Plant Sci 4:442. https://doi.org/10.3389/ fpls.2013.00442

Correa J, Postma JA, Watt M, Wojciechowski T (2019) Soil compaction and the architectural plasticity of root systems. J Exp Bot. https://doi.org/10.1093/jxb/erz383

Des Marais DL, Hernandez KM, Juenger TE (2013) Genotype-by-environment interaction and plasticity: exploring genomic responses of plants to the abiotic environment. Annu Rev Ecol Evol Syst 44:5-29. https://doi.org/10. 1146/annurev-ecolsys-110512-135806

Eavis BW (1972) Soil physical conditions affecting seedling growth I. Mechanical impedance, aeration and moisture availability as influenced by bulk density and moisture levels in a sandy loam soil. Plant Soil 36:613-622. https:// doi.org/10.1007/BF01373511

Eissenstat DM (1992) Costs and benefits of constructing roots of small diameter. J Plant Nutr 15:763-782. https://doi. org/10.1080/01904169209364361

Eissenstat DM, Yanai RD (1997) The ecology of root lifespan. Adv Ecol Res 27:1-60. https://doi.org/10.1016/S00652504(08)60005-7

Goss MJ (1977) Effects of mechanical impedance on root growth in barley (Hordeum vulgare L.) I. Effects on the 
elongation and branching of seminal root axes. $\mathrm{J}$ Exp Bot 28:96-111. https://doi.org/10.1093/jxb/28.1.96

Goss MJ, Russell RS (1980) Effects of mechanical impedance on root growth in barley (Hordeum vulgare L.): III. OBSERVATIONS ON THE MECHANISM OF RESPONSE. J Exp Bot 31:577-588. https://doi.org/10. 1093/jxb/31.2.577

Grzesiak S, Grzesiak MT, Filek W, Hura T, Stabryła J (2002) The impact of different soil moisture and soil compaction on the growth of triticale root system. Acta Physiol Plant 24:331-342. https://doi.org/10.1007/s11738-002-0059-8

Grzesiak MT, Ostrowska A, Hura K, Rut G, Janowiak F, Rzepka A, Hura T, Grzesiak S (2014) Interspecific differences in root architecture among maize and triticale genotypes grown under drought, waterlogging and soil compaction. Acta Physiol Plant 36:3249-3261. https://doi.org/ 10.1007/s11738-014-1691-9

Håkansson I, Voorhees WB, Riley H (1988) Vehicle and wheel factors influencing soil compaction and crop response in different traffic regimes. Soil till Res 35:239-282. https:// doi.org/10.1016/0167-1987(88)90003-7

Jackson RB, Mooney HA, Schulze ED (1997) A global budget for fine root biomass, surface area, and nutrient contents. Proc Natl Acad Sci USA 94:7362-7366. https://doi.org/ 10.1073/pnas.94.14.7362

Jin K, Shen J, Ashton RW, White RP, Dodd IC, Phillips AL, Parry MA, Whalley WR (2015) The effect of impedance to root growth on plant architecture in wheat. Plant Soil 392:323-332. https://doi.org/10.1007/s11104-015-2462-0

Kolb E, Legué V, Bogeat-Triboulot MB (2017) Physical rootsoil interactions. Phys Biol 14:065004. https://doi.org/10. 1088/1478-3975/aa90dd

Lipiec J, Stępniewski W (1995) Effects of soil compaction and tillage systems on uptake and losses of nutrients. Soil till Res 35:37-52. https://doi.org/10.1016/0167-1987(95) 00474-7

Love MI, Huber W, Anders S (2014) Moderated estimation of fold change and dispersion for RNA-seq data with DESeq2. Genome Biol 15(12):550. https://doi.org/10. 1186/s13059-014-0550-8

Lucas M, Schlüter S, Vogel H, Vetterlein D (2019) Roots compact the surrounding soil depending on the structures they encounter. Sci Rep 9:16236. https://doi.org/10.1038/ s41598-019-52665-w

MacInnes CB, Albert LS (1969) Effect of light intensity and plant size on rate of development of early boron deficiency symptoms in tomato root tips. Plant Physiol 44:965-967. https://doi.org/10.1104/pp.44.7.965

Masle J (1992) Genetic variation in the effects of root impedance on growth and transpiration rates of wheat and barley. Aust J Plant Physiol 19:109-125. https://doi.org/10. 1071/PP9920109

Masle J, Passioura JB (1987) The effect of soil strength on the growth of young wheat plants. Aust J Plant Physiol 14:643-656. https://doi.org/10.1071/PP9870643

Materechera SA, Alston AM, Kirby JM, Dexter AR (1992) Influence of root diameter on the penetration of seminal roots into a compacted subsoil. Plant Soil 144:297-303. https://doi.org/10.1007/BF00012888

McConnaughay KDM, Coleman JS (1999) Biomass allocation in plants: ontogeny or optimality? A test along three resource gradients. Ecology 80:2581-2593. https://doi. org/10.1890/0012-9658(1999)080[2581:BAIPOO]2.0. $\mathrm{CO} ; 2$

Mendiburu F (2012) Agricolae: statistical procedures for agricultural research. $\mathrm{R}$ package version 1.1-1. https://cran. rproject.org/web/packages/agricolae/index.html. Accessed 23 Oct 2019

Nakhforoosh A, Bodewein T, Fiorani F, Bodner G (2016) Identification of water use strategies at early growth stages in durum wheat from shoot phenotyping and physiological measurements. Front Plant Sci 7:1155. https://doi.org/10. 3389/fpls.2016.01155

Negin B, Moshelion M (2016) The advantages of functional phenotyping in pre-field screening for drought-tolerant crops. Funct Plant Biol 44:107-118. https://doi.org/10. 1071/FP16156

Nortjé GP, van Hoven W, Laker MC (2012) Factors affecting the impact of off-road driving on soils in an area in the Kruger National Park, South Africa. Environ Manage 50:1164-1176. https://doi.org/10.1007/ s00267-012-9954-y

Oldeman LR, Hakkeling RTA, Sombroek WG (1991) World map of the status of human-induced soil degradation: an explanatory note. International Soil Reference and Information Centre, Wageningen

Palmer AR (2012) Developmental plasticity and the origin of novel forms: unveiling cryptic genetic variation via "Use and Disuse.” J Exp Zoo B Mol Dev Evol 318:466-479. https://doi.org/10.1002/jez.b.21447

Passioura JB (2002) Soil conditions and plant growth. Plant Cell Environ 25:311-318. https://doi.org/10.1046/j.00168025.2001.00802.x

Pfeifer J, Faget M, Walter A, Blossfeld S, Fiorani F, Schurr U, Nagel KA (2014) Spring barley shows dynamic compensatory root and shoot growth responses when exposed to localised soil compaction and fertilisation. Funct Plant Biol 41:581-597. https://doi.org/10.1071/FP13224

Pierce FJ, Larson WE, Dowdy RH, Graham WAP (1983) Productivity of soils: assessing long-term changes due to erosion. J Soil Water Conserv 38:39-44

Pigliucci M, Pigliucci P of E and ED of BM (2001) Phenotypic plasticity: beyond nature and nurture. JHU Press

Popova L, van Dusschoten D, Nagel KA, Fiorani F, Mazzolai B (2016) Plant root tortuosity: an indicator of root path formation in soil with different composition and density. Ann Bot 118:685-698. https://doi.org/10.1093/aob/mcw057

Pregitzer KS, Laskowski MJ, Burton AJ, Lessard VC, Zak DR (1998) Variation in sugar maple root respiration with root diameter and soil depth. Tree Physiol 18:665-670. https:// doi.org/10.1093/treephys/18.10.665

R Core Team (2018) R: A language and environment for statistical computing. https://www.R-project.org/. Accessed 23 Oct 2019

Rebetzke GJ, Kirkegaard JA, Watt M, Richards RA (2014) Genetically vigorous wheat genotypes maintain superior early growth in no-till soils. Plant Soil 377:127-144. https://doi.org/10.1007/s11104-013-1985-5

Reich PB (2002) Root-shoot relations: optimality in acclimation and adaptation or the "Emperor's new clothes"”? In: Waisel Y, Eshel A, Kafkafi U (eds) Plant roots-the hidden half. Marcel Dekker, New York, pp 205-220 
Sinha S, Kumaravadivel N (2016) Understanding genetic diversity of sorghum using quantitative traits. Scientifica (cairo) 2016:3075023. https://doi.org/10.1155/2016/ 3075023

Stirzaker RJ, Passioura JB, Wilms Y (1996) Soil structure and plant growth: Impact of bulk density and biopores. Plant Soil 185:151-162. https://doi.org/10.1007/BF02257571

Sultan SE (1987) Evolutionary implications of phenotypic plasticity in plants. In: Hecht MK, Wallace B, Prance GT (eds) Evolutionary biology. Springer, New York, pp 127-178

To J, Kay BD (2005) Variation in penetrometer resistance with soil properties: the contribution of effective stress and implications for pedotransfer functions. Geoderma 126:261-276. https://doi.org/10.1016/j.geoderma.2004. 08.006

Tubeileh A, Groleau-Renaud V, Plantureux S, Guckert A (2003) Effect of soil compaction on photosynthesis and carbon partitioning within a maize-soil system. Soil till Res 71:151-161. https://doi.org/10.1016/S0167-1987(03) 00061-8

Unger PW, Kaspar TC (1994) Soil compaction and root growth: a review. Agron J 86:759-766. https://doi.org/10. 2134/agronj1994.00021962008600050004x
Via S, Gomulkiewicz R, De Jong G et al (1995) Adaptive phenotypic plasticity: consensus and controversy. Trends Ecol Evol 10:212-217. https://doi.org/10.1016/S01695347(00)89061-8

Wallace A (1986) Definition of stresses in crop productioniron, plant nutrient, and non-nutrient stress interactions. J Plant Nutr 9:187-192. https://doi.org/10.1080/01904 168609363436

Weiner J (2004) Allocation, plasticity and allometry in plants. Perspect Plant Ecol Evol Syst 6:207-215. https://doi.org/ 10.1078/1433-8319-00083

Whalley WR, Leeds-Harrison PB, Clark LJ, Gowing DJG (2005) Use of effective stress to predict the penetrometer resistance of unsaturated agricultural soils. Soil till Res 84:18-27. https://doi.org/10.1016/j.still.2004.08.003

Wickham H (2009) ggplot2: elegant graphics for data analysis. Springer, New York

Publisher's Note Springer Nature remains neutral with regard to jurisdictional claims in published maps and institutional affiliations. 